\title{
The Influence of Design Parameters on Straight Bevel Gear Dynamics
}

\author{
Chiu-Fan Hsieh ${ }^{1} \&$ You-Qing Zhu ${ }^{1}$ \\ ${ }^{1}$ Department of Mechanical and Computer-Aided Engineering, National Formosa University, Taiwan \\ Correspondence: Chiu-Fan Hsieh, Department of Mechanical and Computer-Aided Engineering, National \\ Formosa University, 64 Wunhua Road, Huwei, Yunlin, Taiwan. E-mail: cfhsieh@nfu.edu.tw
}

Received: June 8, 2015 Accepted: June 27, 2015 Online Published: November 13, 2015

doi:10.5539/mer.v5n2p114 URL: http://dx.doi.org/10.5539/mer.v5n2p114

\begin{abstract}
This study analyzes the influence of design parameters on the dynamics of straight bevel gears by constructing a model that allows variation in the shaft angle, pressure angle, and backlash. According to the statistical analysis, the order of influence of these parameters on weight is shaft angle $>$ pressure angle $>$ backlash. When the shaft angle is $90^{\circ}$, the statistical results show the drive is stable and the stress fluctuation level is low. The pressure angle, on the other hand, can affect the gear's dynamic property by influencing the driving component force on the gear and the component force on the shaft. The results for the shaft and pressure angles are used to determine the appropriate backlash. Overall, the analysis not only provides designers with an important reference but explains the dominance in the market of gear designs with a $90^{\circ}$ shaft angle and a $20^{\circ}$ pressure angle.
\end{abstract}

Keywords: bevel gears, shaft angle, pressure angle, backlash, dynamics, stress

\section{Introduction}

Bevel gears, primarily of spiral, hypoid, and straight types, are widely used on the power transmission of concurrent axes and alternating axes. In general, the shaft angle of a bevel gear is designed to be $90^{\circ}$ with a maximum reduction ratio of 10 , leading to high efficiency and high precision. In particular, the design must meet the spatial surface meshing condition, and the gear blank and tooth form designs must be able to vary with different cutting methods (Litvin et al., 1987). The calculation of bevel gears is thus more complicated than for other gear types (Fong \& Tsay, 1991, 1992) and requires the development of special design software. The most common type of bevel gear is the straight bevel gear, which is applied to power transmissions between concurrent axes. This gear is characterized by a straight tooth whose depth decreases gradually from large to tip end. The theoretical tooth form is involute (Al-Daccak et al., 1994), but the tooth form designs vary with different manufacturing methods. Compared to other bevel gears, however (e.g. the spiral bevel gear), the configuration is simple and the gear easily made, forged, and shaped. As a result, the bevel differential mechanism is used extensively in the market.

As regards research on the straight bevel gear, most studies have focused on the theoretical mathematical model of gear (Tsai \& Chin, 1987; Chang \& Tsay, 2000; Figliolini \& Angeles, 2004), teeth contact analysis (Jiao \& Cao, 2011; Kolivand et al., 2015), finite element modeling and analysis (Nalluveettil \& Muthuveerappan, 1993), teeth deflection analysis (Gagnon et al., 1997), manufacturing techniques and cutting methods (Özel et al., 2005; Shih \& Fong, 2008; Shih, 2012; Fuentes et al., 2011; Tsuji et al., 2013; Kawasaki et al., 2015), measurement technique (Kawasaki \& Shinma, 2009), lubrication regime (Ghahnavieh et al., 2014) and dynamic behavior of two-stage straight bevel gear (Yassine et al., 2014). To the best of our knowledge, however, no work exists on the influence of dynamic contact stress and gear design parameters on straight bevel gear dynamics. Hence, this study assesses the influence of a straight bevel gear's main design parameters (shaft angle, pressure angle, and backlash) on its dynamics by constructing a dynamics analysis model that weights the influence of the various parameters. The results provide a useful reference for straight bevel gear design.

\section{Dynamics Analysis Model for a Straight Bevel Gear}

\subsection{Straight Bevel Gear Modeling}

First, using Solidworks, a straight bevel gear CAD model is built in which the tooth form is created based on a mathematical model. Here, the modulus is 2 , the number of teeth is 15 , the pressure angle is $20^{\circ}$, the shaft angle is $90^{\circ}$, and the backlash is 0.2 . The building of this model is described below and linked to the illustrations in Figure 1: 
Step1: A blank is created with a shaft angle of $90^{\circ}$ (a);

Step2: The involute profile is drawn on the gear plane (b);

Step3: A straight bevel gear tooth form is cut along the conical point of involute profile (c);

Step4: The required teeth are cut in a ring array to complete a straight bevel gear (d); and then

Step5: Another straight bevel gear (45 teeth) is built following the above steps, and the two straight bevel gears are combined (e).

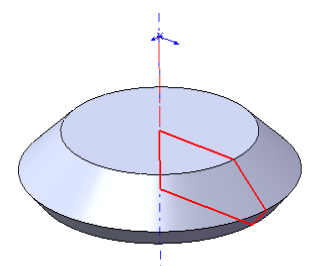

(a) Blank is created

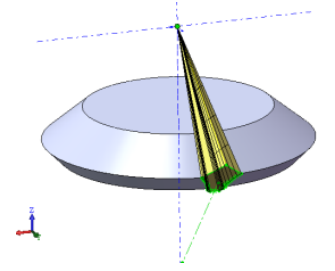

(c) One tooth form is cut

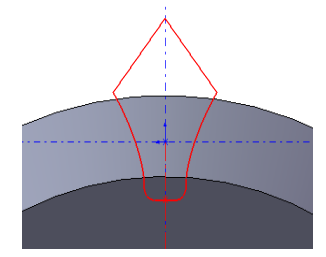

(b) Involute profile is drawn

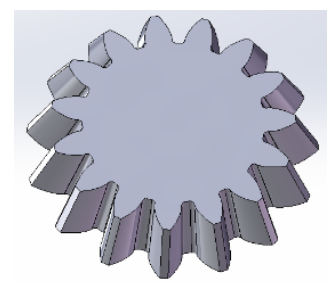

(d) Overall tooth form is cut

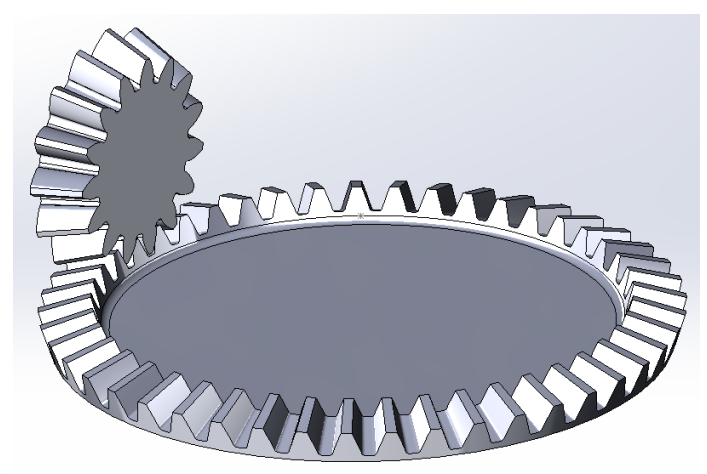

(e) The straight bevel gear is assembled

Figure 1. Construction of the straight bevel gear

\subsection{Dynamics Analysis Model}

To construct the dynamic analysis model, it employs a systematic dynamics calculation model for an experimentally validated cycloidal speed reducer (Hsieh, 2014), whose applications include testing traditional, improved, and novel designs and identifying their shortcomings and advantages (Hsieh, 2014). These modeling and calculation techniques (Hsieh, 2014) allow constructing a dynamic analysis model of the straight bevel gear. In this paper, the gear modulus is fixed at 2, the driving gear is set at 15 teeth, and the driven gear is at 45 teeth. The simulated conditions include total run duration of $1.5 \mathrm{sec}$ and the driving gear rotation speed set at a constant $120 \mathrm{rpm}(720 \mathrm{deg} / \mathrm{s})$. The contact pattern is a 3D collision mode, and gravity acceleration is 9.81 $\mathrm{m} / \mathrm{sec}^{\wedge} 2$. The material is alloy steel whose mechanical properties are given in Table 1 .

In the stress analysis, stress can be calculated by the finite element method using SolidWorks (Hsieh, 2014). During bevel gear motion, the variations in gear contact stress can be measured over time. First, the triangular mesh is calculated. If the values obtained when calculating gear engagement are to be accurate, the grid density 
in the place without gear contact can be low, but the grid density in the place with gear contact must be high. Grid computation is shown in Figure 2(a) and stress calculation in Figure 2(b).

The material used in all models and the friction factor are the same. Assuming the loading at the driven gear is fixed as $5 \mathrm{~N}-\mathrm{m}$, the effect on dynamics was carried out by giving different driving torque, which includes 15 $\mathrm{N}-\mathrm{m}, 30 \mathrm{~N}-\mathrm{m}, 45 \mathrm{~N}-\mathrm{m}, 60 \mathrm{~N}-\mathrm{m}, 75 \mathrm{~N}-\mathrm{m}$ and $90 \mathrm{~N}-\mathrm{m}$, respectively. Thus, different parameter design values are assigned to the straight bevel gear model that result in different motion and stress variations. The tooth profile design parameters are pressure angle, shaft angle, and backlash, whose parameter value settings are listed in Table 2. To assess the influence of parameter design on the straight bevel gear's dynamics, these parameter values are cross related, producing 27 groups as simulation subjects in each driving torque case.

Table 1. Mechanical properties of the material

\begin{tabular}{ccccc}
\hline \multirow{2}{*}{ Material } & \multicolumn{4}{c}{ Mechanical properties N/mm^2 } \\
\cline { 2 - 5 } & Elastic modulus & Shear modulus & Tensile strength & Yield strength \\
\hline Alloy steel & 210,000 & 79,000 & 723.1025 & 620.422 \\
\hline
\end{tabular}

Table 2. Gear design parameter values in each driving torque case

\begin{tabular}{cccc}
\hline \multirow{2}{*}{ Numerical } & \multicolumn{3}{c}{ Parameter } \\
\cline { 2 - 4 } & Pressure angle & Backlash & Shaft angle \\
\hline 1 & $14.5^{\circ}$ & 0.1 & $45^{\circ}$ \\
2 & $20^{\circ}$ & 0.3 & $60^{\circ}$ \\
3 & $25^{\circ}$ & 0.5 & $90^{\circ}$ \\
\hline
\end{tabular}

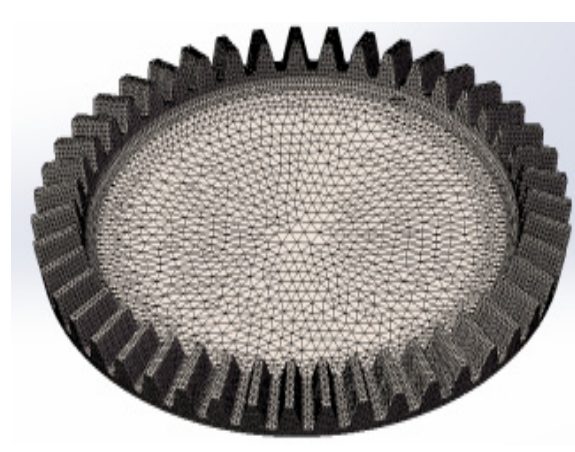

(a) Grid chart

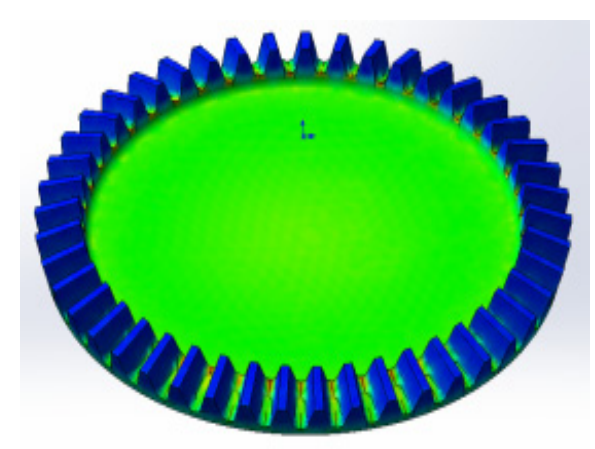

(b) Schematic diagram of stress

Figure 2. Stress analysis model

\subsection{Dynamics Analysis}

In the dynamics analysis, for example, the driving torque is $15 \mathrm{~N}-\mathrm{m}$, the fixed pressure angle is $20^{\circ}$, the backlash is $0.1 \mathrm{~mm}$, and the variable shaft angle is $45^{\circ}, 60^{\circ}$, and $90^{\circ}$ respectively. The following results are obtained based on the data from one revolution of the driving gear. The time interval of calculation is 0.0013889 s. Figures 3 and 4 show the analytic results of the angular velocity and angular acceleration of the driven gear. The velocity fluctuation is regular in all three shaft angle designs, but the $60^{\circ}$ shaft angle has the maximum fluctuation. The angular acceleration analysis further reveals that the $60^{\circ}$ shaft angle has the maximum peak values. Although one explanation could be larger vibrations, when the shaft angle is $90^{\circ}$, the minimum angular velocity fluctuation and acceleration reach peak values, so the motion is relatively stable and the vibration slight. 


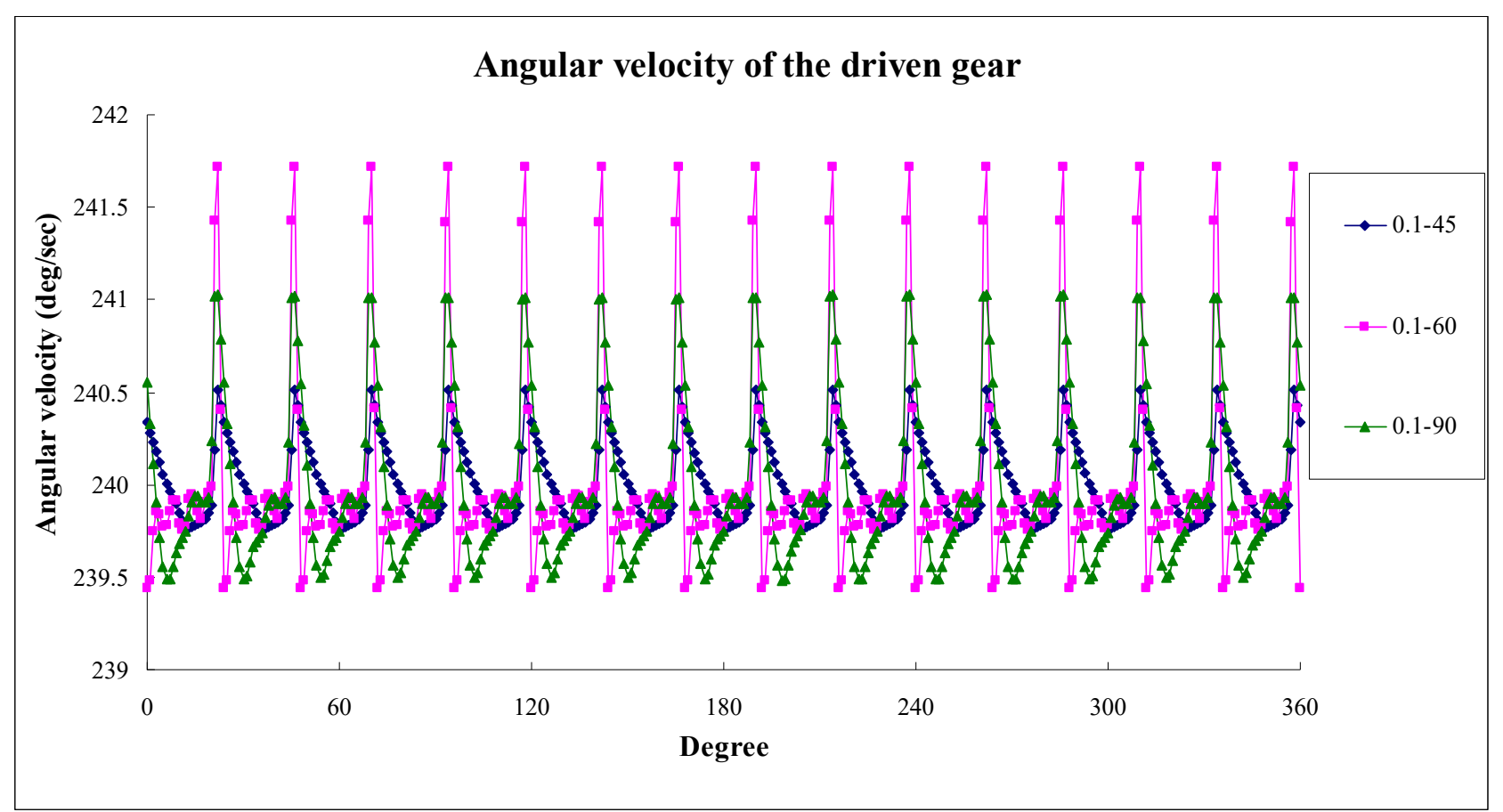

Figure 3. Angular velocity of the driven gear

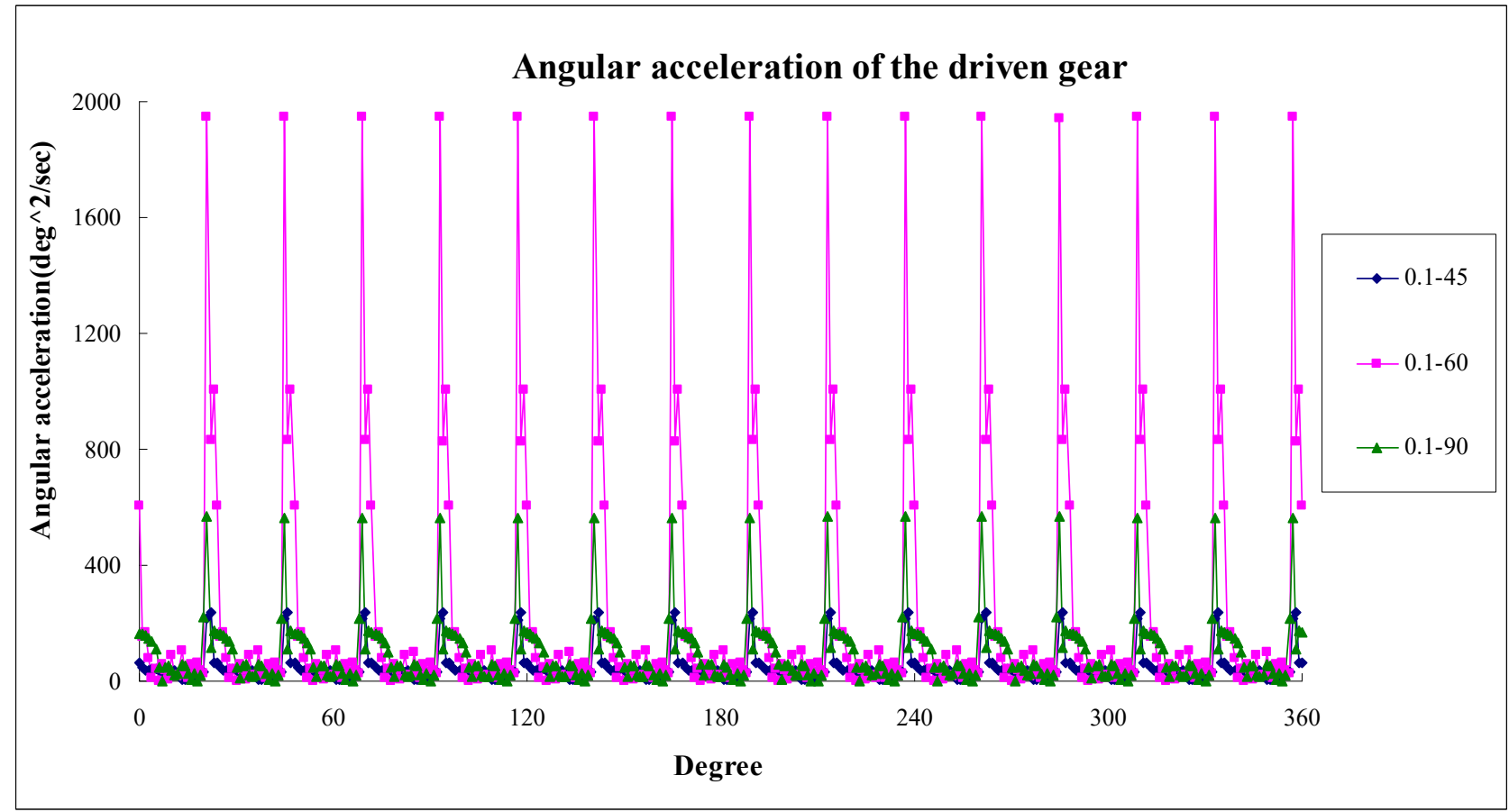

Figure 4. Angular acceleration of the driven gear 


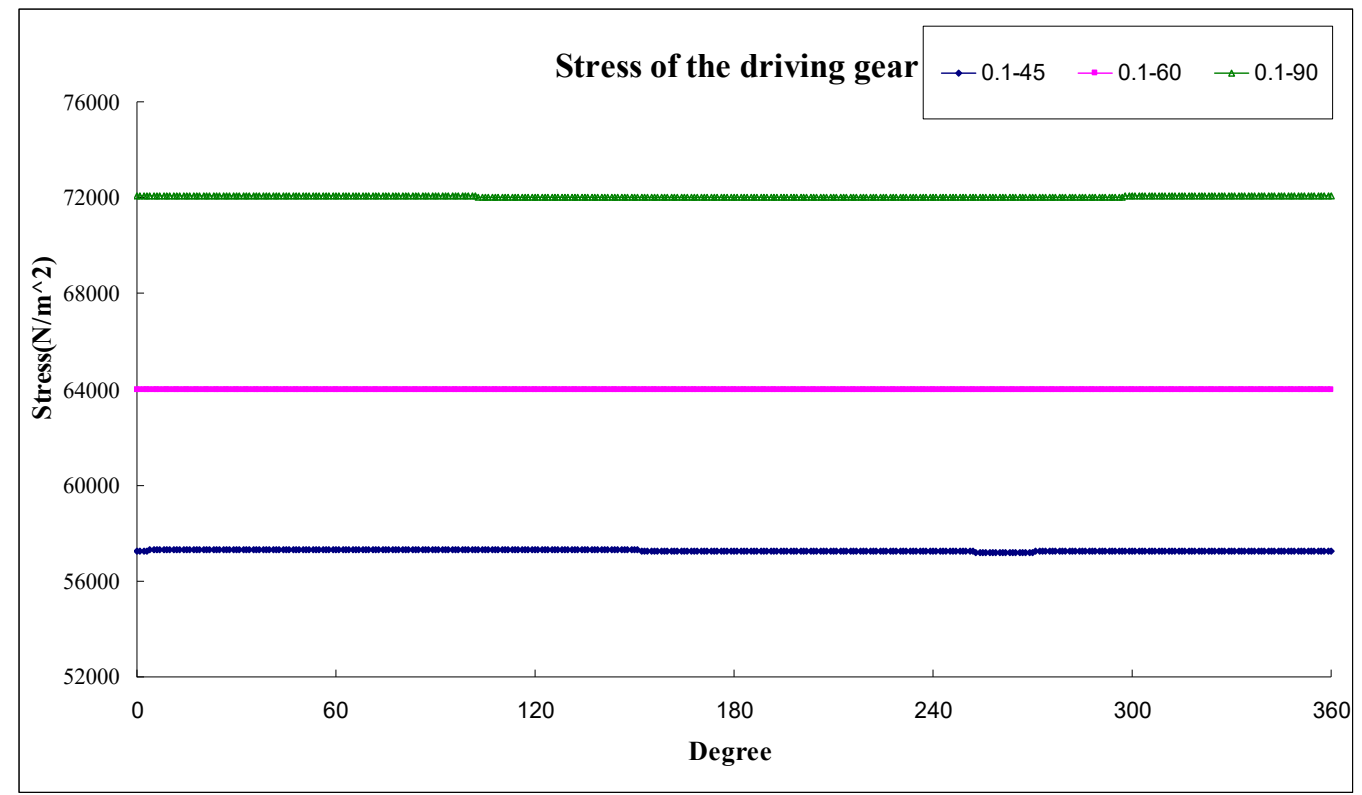

(a)
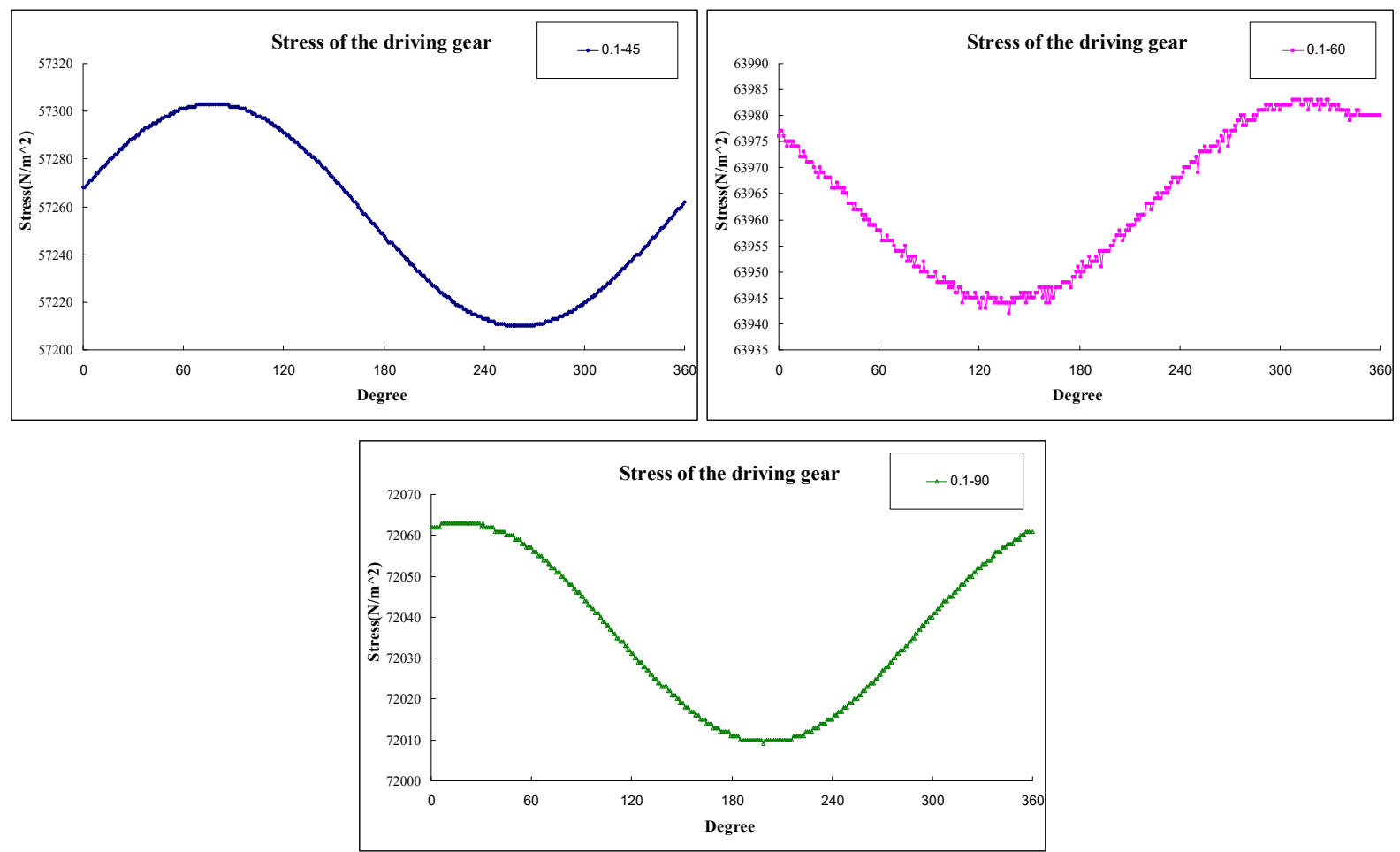

(b)

Figure 5. Stress variation of driving gear

According to the stress analysis, the axial component force increases with the shaft angle, while the stress of the driving gear increases gradually (Figure 5(a)). As Figure 5(b) shows, the three stress curves of the driving gear fluctuate regularly but slightly. When the shaft angle is $90^{\circ}$, the average stress is maximum about $72000 \mathrm{~N} / \mathrm{m}^{\wedge} 2$; when the shaft angle is $60^{\circ}$, the average stress is about $64000 \mathrm{~N} / \mathrm{m}^{\wedge} 2$; and when the shaft angle is $45^{\circ}$, the average stress is minimum about $57000 \mathrm{~N} / \mathrm{m}^{\wedge} 2$. 


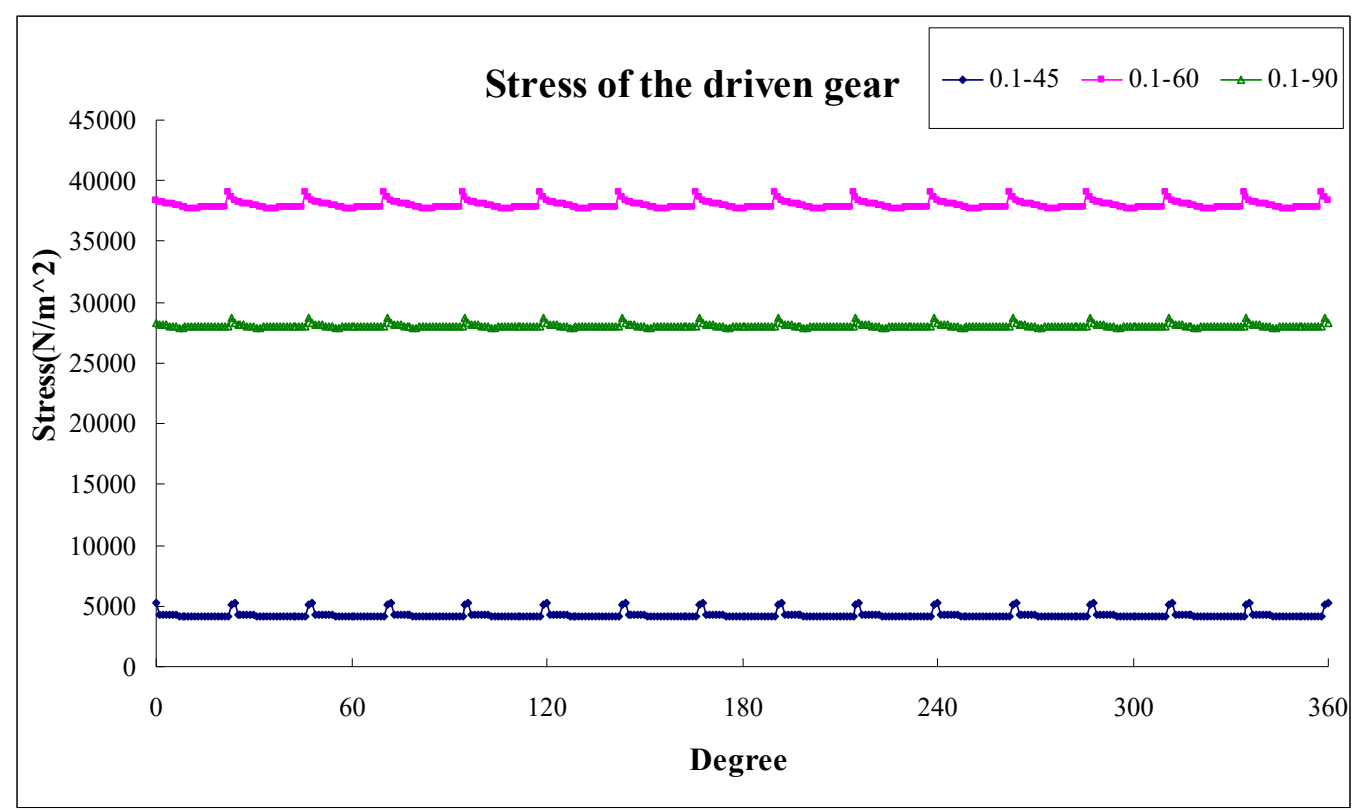

(a)
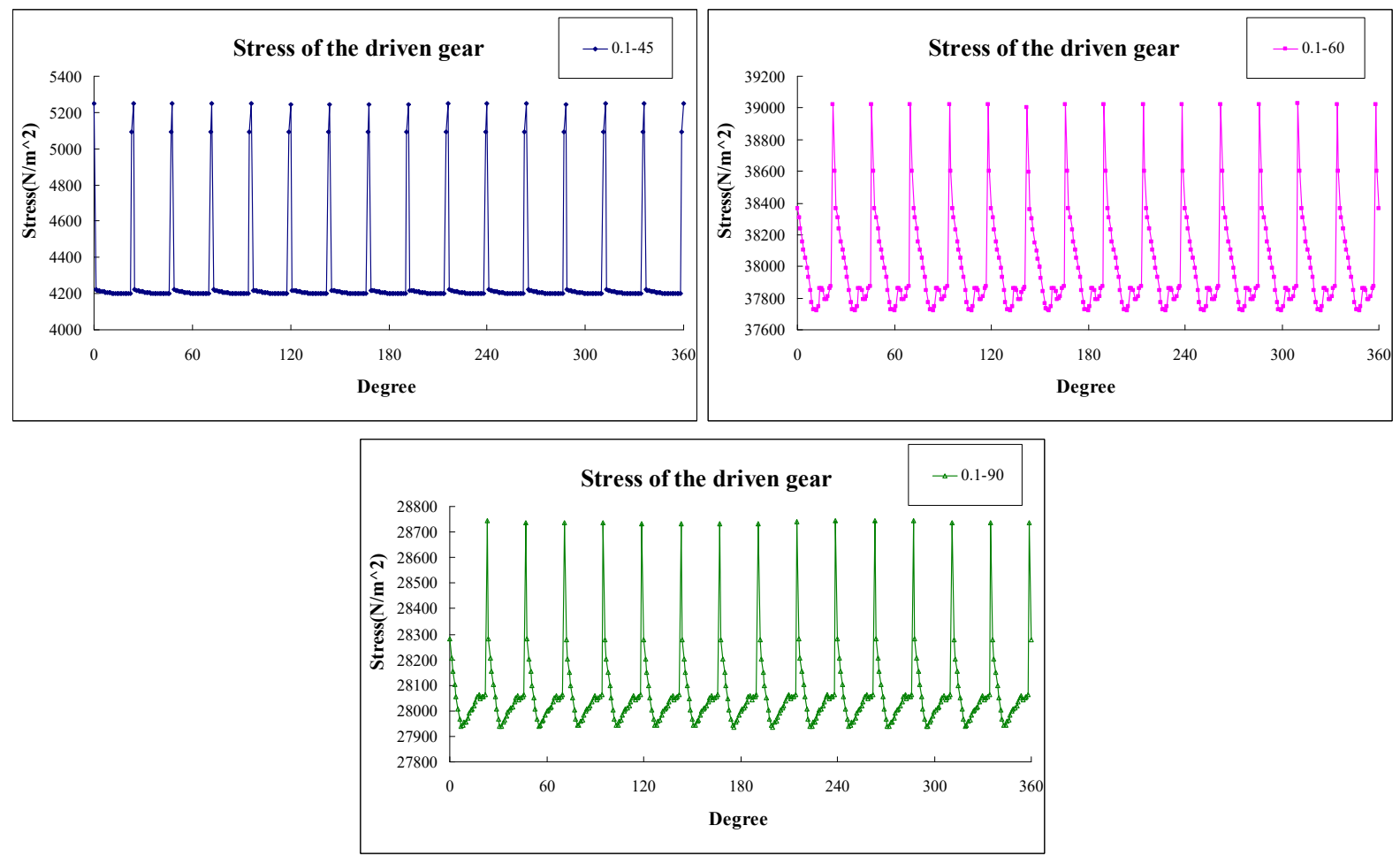

(b)

Figure 6. Stress variation of driven gear

The stress of the driven gear is as shown in Figure 6. The stress peaks are all regular (Figure 6(b)). In this case, the maximum average stress is the shaft angle $60^{\circ}$ after that is the shaft angle $90^{\circ}$, and the minimum average stress is the shaft angle $45^{\circ}$. Since the stress ripple coefficient (Hsieh, 2014) can indicate the stress fluctuation level, the calculation result shows the hierarchy of the stress ripple level is as shaft angle $45^{\circ}>$ shaft angle $60^{\circ}$ $>$ shaft angle $90^{\circ}$. This analysis thus suggests a shaft angle of $90^{\circ}$ as an ideal design.

The stress analysis can indicate the contact stress condition, thus would affect the life of the components. For comparing, each driving torque case includes 27 sets of stress data. 
Since the rotation speed setting is on the driving gear, only the stress of the driven gear is analyzed and discussed. The equation of standard deviation can be expressed as

$$
S_{d}^{(i)}=\frac{1}{N} \sqrt{N \Sigma \sigma^{2}-(\Sigma \sigma)^{2}}, i=1 \sim 27
$$

where $N$ is the number of stress data for one revolution of the driving gear. $\sigma$ is the stress data of the driven gear.

In order to compare the stress variation level, the coefficient of variation can be defined as

$$
C_{v}^{(i)}=\frac{S_{d}}{\bar{\sigma}} \times 100, i=1 \sim 27
$$

In which, $\bar{\sigma}$ means the average stress of the driven gear.

Here, the influences of the backlash, pressure angle and the shaft angle parameters, the equations are defined respectively as

$$
\begin{gathered}
B_{m}=\sum_{j=1}^{9} C_{v, m}^{(j)}, \quad m=0.1,0.3,0.5 \\
P_{n}=\sum_{j=1}^{9} C_{v, n}^{(j)}, \quad n=14.5,20,25 \\
S_{o}=\sum_{j=1}^{9} C_{v, o}^{(j)}, \quad o=45,60,90
\end{gathered}
$$

In this paper, the tendency of a whole influence is calculated by sum of variation coefficient of each driving torque case as follows:

$$
\begin{gathered}
S B_{m}=B_{m}^{(15)}+B_{m}^{(30)}+B_{m}^{(45)}+B_{m}^{(60)}+B_{m}^{(75)}+B_{m}^{(90)}, m=0.1,0.3,0.5 \\
S P_{n}=P_{n}^{(15)}+P_{n}^{(30)}+P_{n}^{(45)}+P_{n}^{(60)}+P_{n}^{(75)}+P_{n}^{(90)}, n=14.5,20,25 \\
S S_{o}=S_{o}^{(15)}+S_{o}^{(30)}+S_{o}^{(45)}+S_{o}^{(60)}+S_{o}^{(75)}+S_{o}^{(90)}, o=45,60,90
\end{gathered}
$$

\section{Statistical Results and Discussion}

\subsection{Influence on Dynamics of the Backlash Parameter}

As shown in Figure 7 (a), when the backlash is small $(0.1 \mathrm{~mm})$, the gear collision frequency and gear vibration will increase and the gear contact travel will extend to increase the stress. Thus, the variation coefficients in most driving torque cases are the largest. The whole tendency shows that the stress ripple level would relieve with the increasing of backlash as shown in Figure 8(a). When the backlash is large, in contrast, the collision between gears can be reduced, although there will be energy loss in the power transmission, reducing transmission efficiency. The maximum variation coefficient in backlash parameter is the smallest (see Figure 8) among the three parameters, thus it has the minimum influence comparing to the other parameters. Accordingly, the main influence on stress and fluctuation occurs at the shaft angle and pressure angle, an appropriate backlash value should be determined based on their design and working condition.

\subsection{Influence on Dynamics of the Pressure Angle Parameter}

The variation coefficient results show the influence degree of the pressure angle parameter is between the backlash and shaft angle parameters in Figures 7 and 8. In the driven gear, the stress ripple level would be increased with the decreasing of the pressure angle especially at $14.5^{\circ}$, which load and fluctuation are the largest. Apparently, the gear driving component force and stress fluctuation increase as the pressure angle decreases. On the other hand, the larger the pressure angle $\left(25^{\circ}\right)$, the lower the gear driving component force, and the stress fluctuation decreases while the load on the shaft increases. Hence, according to the stress statistical result, a pressure angle of $20^{\circ}$ is a better choice. 


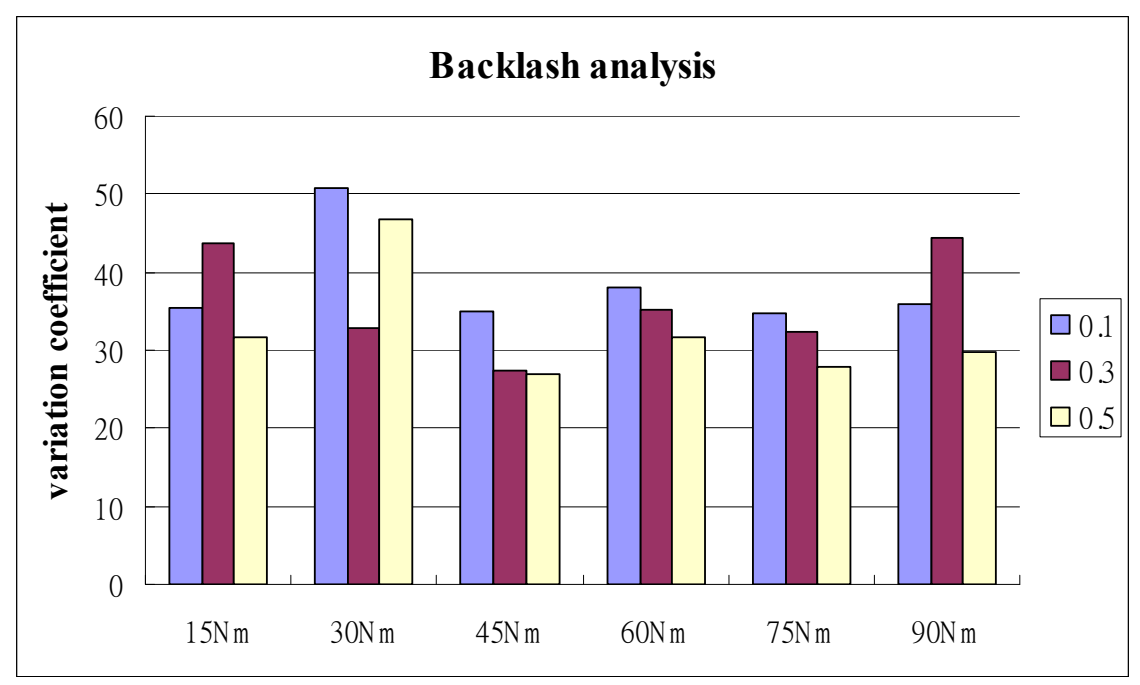

(a) Backlash

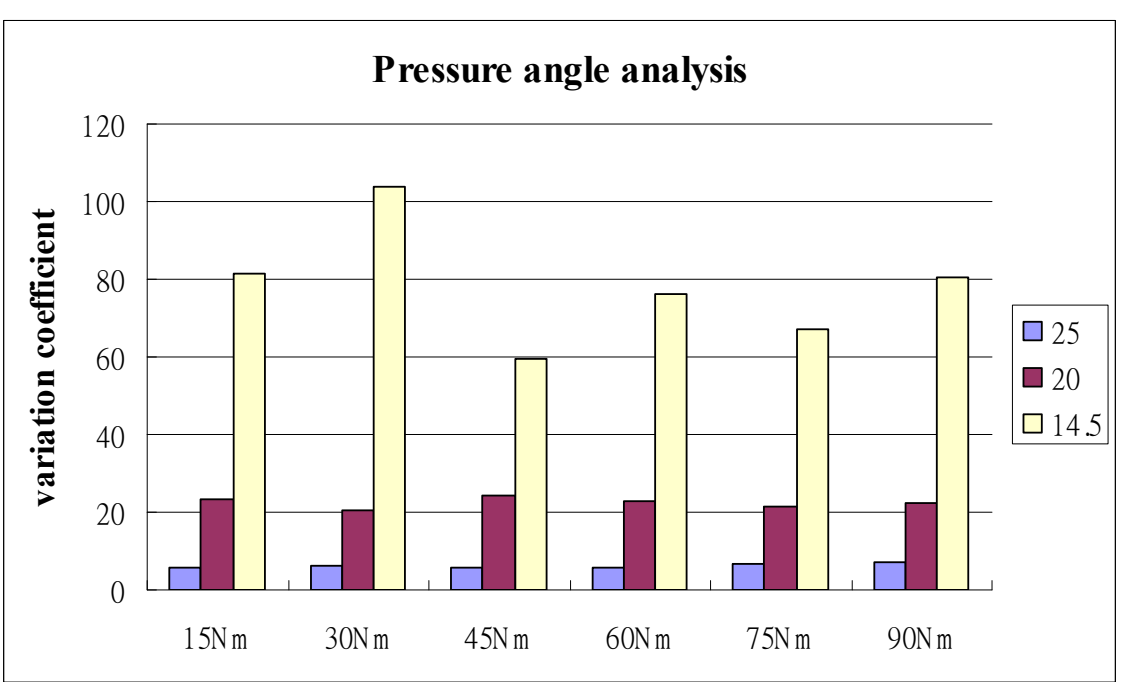

(b) Pressure angle

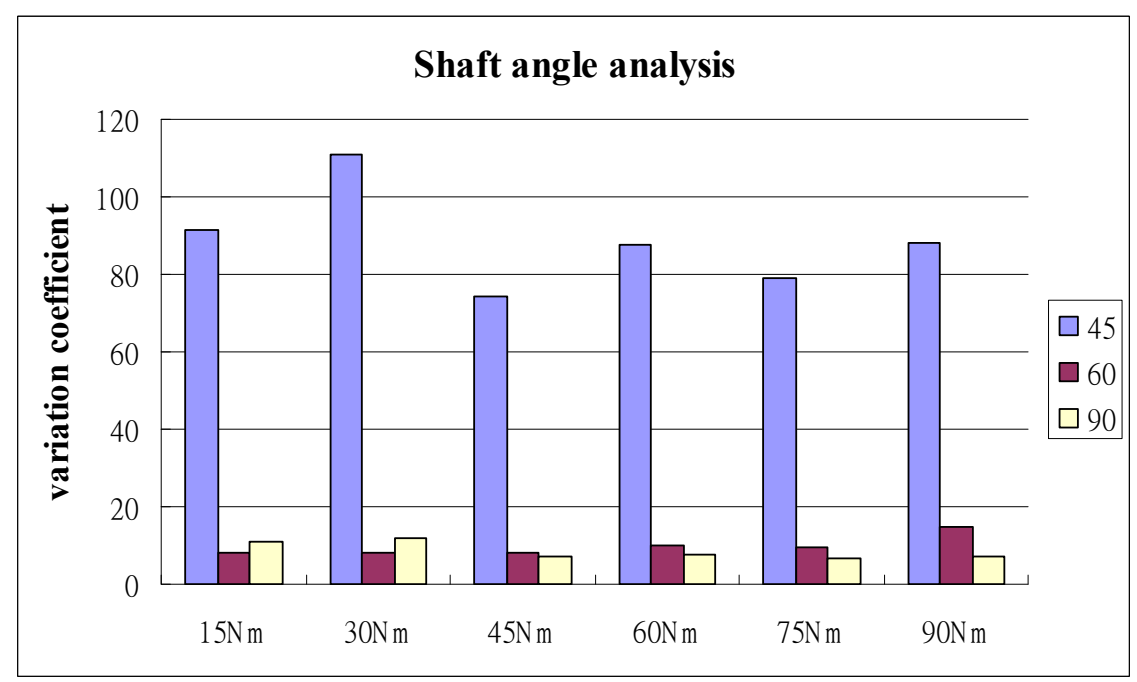

(c) Shaft angle

Figure 7. Statistical results in each driving torque case 


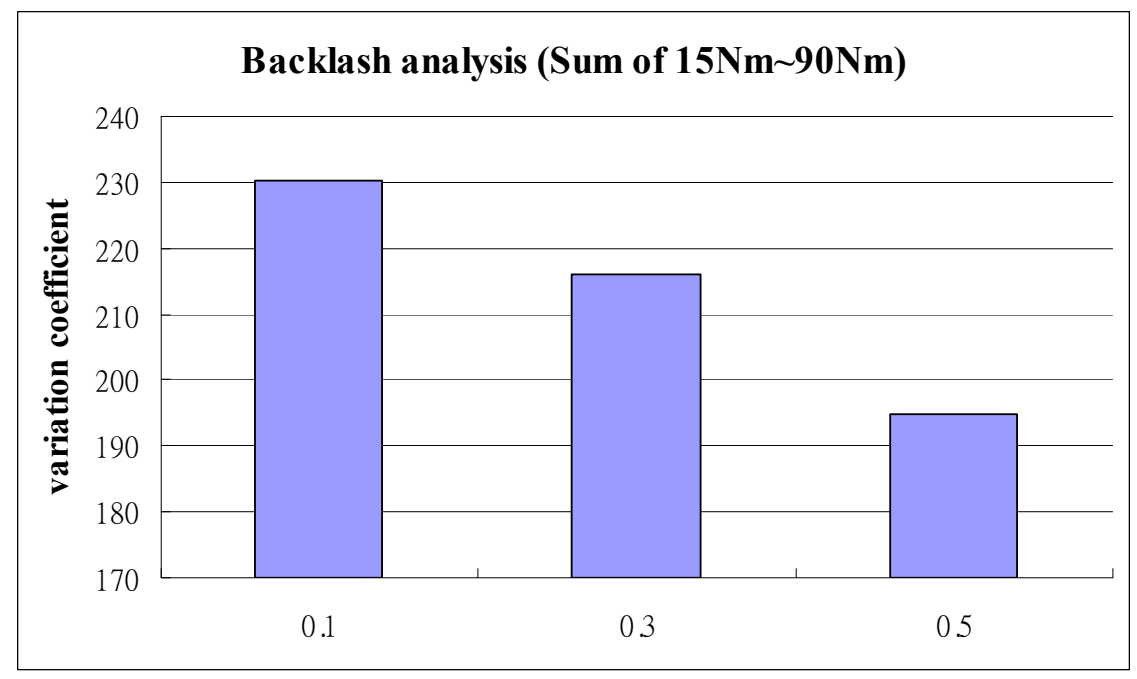

(a) Backlash

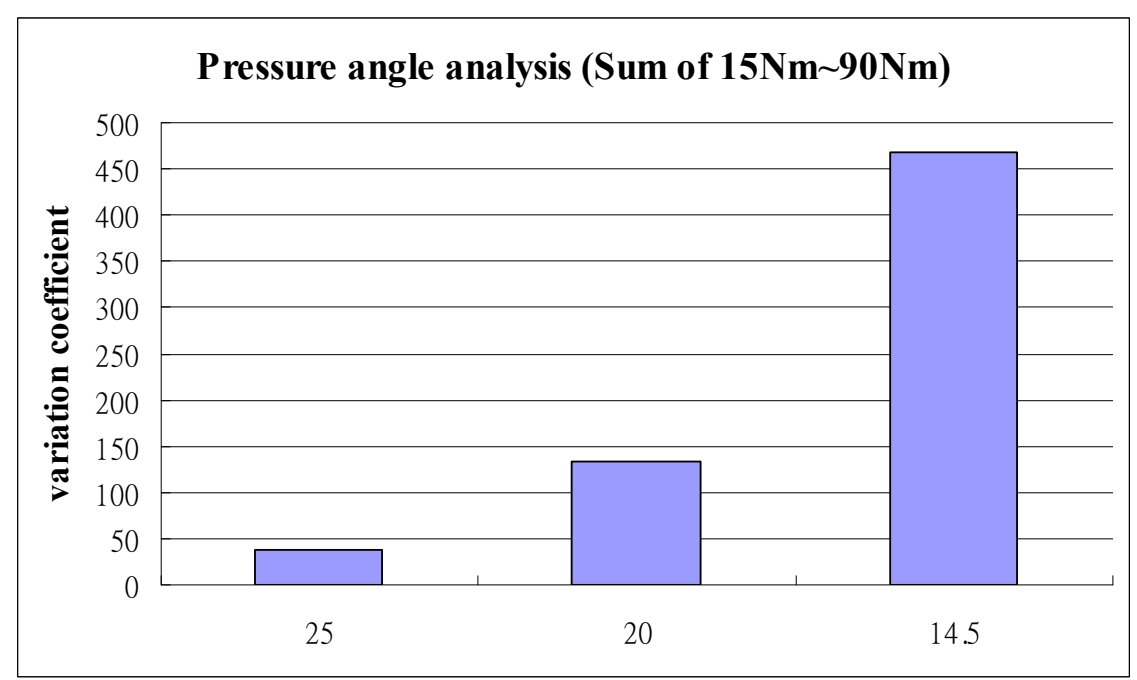

(b) Pressure angle

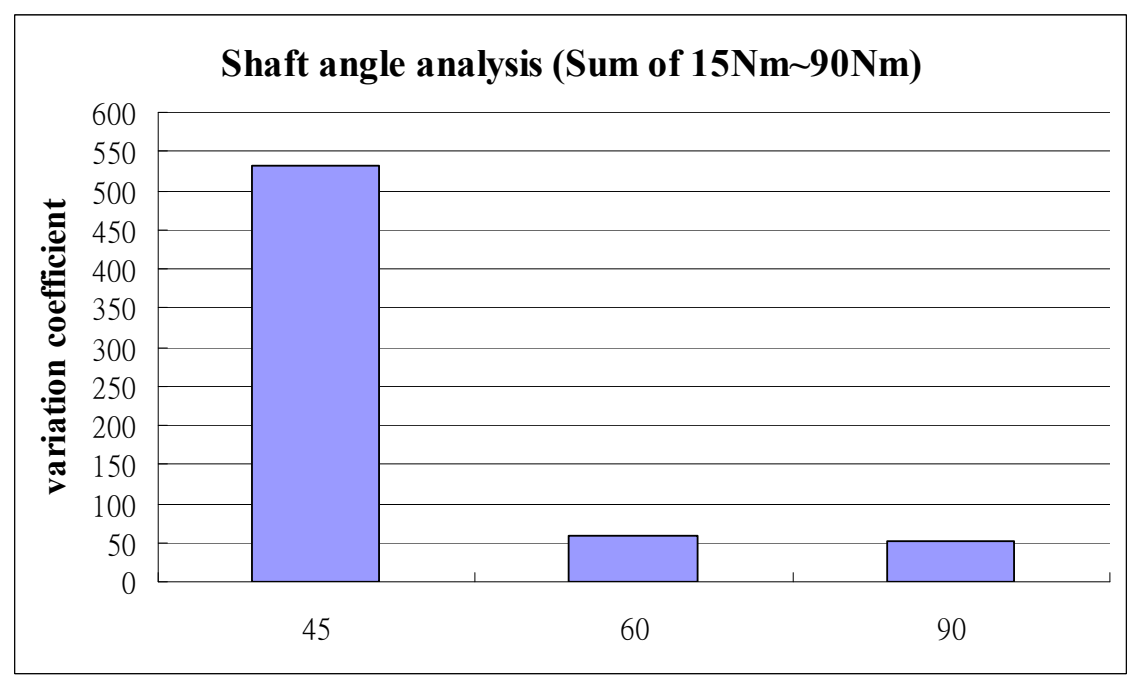

(c) Shaft angle

Figure 8. Statistical results by sum of variation coefficient of each driving torque case 


\subsection{Influence on Dynamics of the Shaft Angle Parameter}

Since the maximum variation coefficient in shaft angle parameter is the largest as shown in Figures 7 and 8, it places the maximum influence on the shaft angle design. The variation coefficient of shaft angle at $45^{\circ}$ is the largest in each driving torque case (see Figure $7(\mathrm{c})$ ). When the shaft angle increases to $60^{\circ}$, the stress fluctuation frequency would obviously reduce. The shaft angle at $90^{\circ}$ is the most stable one and thus has the least stress variation coefficient in most driving torque cases. Furthermore, the shaft angle at $90^{\circ}$ can obtain more stable operation than the case at $60^{\circ}$ under a larger driving torque. Besides, Figure 8 (c) represents the whole tendency in the smaller shaft angle (like shaft angle at $45^{\circ}$ ), however, its combination with other two parameters may not be a better condition. The shaft angle at $90^{\circ}$ can get the lowest variation coefficient. Hence, unless there are special power requirements, the shaft angle at $90^{\circ}$ is recommended as the design basis.

\section{Conclusions}

By constructing a dynamics analysis model for straight bevel gears, this analysis generates accurate shaft angle, pressure angle, and backlash design parameters and then measures the influence of each parameter on the gear's dynamics. From the statistical analysis, the influence of the backlash is not obvious because the variation coefficient is quite similar in different backlash size. However, the size of the backlash still can influence the gear's dynamic properties. The analysis also reveals that the pressure angle can be designed according to load. That is, when the pressure angle is large, the stress and stress fluctuation on the gear can be reduced, but the axial component force is increased, placing a burden on the bearing. The component having the maximum influence on dynamics is the shaft angle, and the shaft angle at $90^{\circ}$ with other two design parameters would be recommended as a better design.

\section{References}

Al-Daccak, M. L., Angeles, J., \& González-Palacios, M. A. (1994). The Modeling of Bevel Gears Using the Exact Spherical Involute. ASME Journal of Mechanical Design, 116, 364-368. http://dx.doi.org/10.1115/1. 2919387

Chang, C. K., \& Tsay, C. B. (2000). Mathematical Model of Straight Bevel Gears with Octoid Form. Journal of the Chinese Society of Mechanical Engineers, 21, 239-245.

Figliolini, G., \& Angeles, J. (2004). Algorithms for involute and octoidal bevel-gear generation. ASME Journal of Mechanical Design, 127(4), 664-672. http://dx.doi.org/10.1115/1.1900147

Fong, Z. H., \& Tsay, C. B. (1991). A Study on the Tooth Geometry and Cutting Machine Mechanisms of Spiral Bevel Gears. ASME Journal of Mechanical Design, 113, 174-181. http://dx.doi.org/10.1115/1.2912788

Fong, Z. H., \& Tsay, C. B. (1992). Kinematical Optimization of Spiral Bevel Gears, ASME Journal of Mechanical Design, 114, 498-506. http://dx.doi.org/10.1115/1.2926578

Fong, Z. H., \& Tsay, C.B. (1991). A Mathematical Model for the Tooth Geometry of Circular-Cut Spiral Bevel Gears. ASME Journal of Mechanical Design, 113, 346-351. http://dx.doi.org/10.1115/1.2912766

Fuentes, A., Iserte, J. L., Gonzalez-Perez, I., \& Sanchez-Marin, F. T. (2011). Computerized Design of Advanced Straight, \& Skew Bevel Gears Produced by Precision Forging. Computer Methods in Applied Mechanics and Engineering, 200, 2363-2377. http://dx.doi.org/10.1016/j.cma.2011.04.006

Gagnon, P., Gosselin, C., \& Cloutier, L. (1997). Analysis of Spur and Straight Bevel Gear Teeth Deflection by the Finite Strip Method. ASME Journal of Mechanical Design, 119, 421-426. http://dx.doi.org/10.1115/1. 2826385

Ghahnavieh, A. B., Akbarzadeh, S., \& Mosaddegh P. (2014). A numerical study on the performance of straight bevel gears operating under mixed lubrication regime. Mechanism and Machine Theory, 75, 27-40. http://dx.doi.org/10.1016/j.mechmachtheory.2014.01.005

Hsieh C. F. (2014). Dynamics analysis of cycloidal speed reducers with pinwheel and nonpinwheel designs. ASME Journal of Mechanical Design, 136(9), 091008. http://dx.doi.org/10.1115/1.4027850

Hsieh C. F. (2014). The effect on dynamics of using a new transmission design for eccentric speed reducers. Mech. Mach. Theory, 80(1), 1-16. http://dx.doi.org/10.1016/j.mechmachtheory.2014.04.020

Hsieh C. F. (2014). Traditional versus improved designs for cycloidal speed reducers with a small tooth difference: The effect on dynamics. Mech. Mach. Theory, 86(1), 15-35. http://dx.doi.org/10.1016/j. mechmachtheory.2014.11.013 
Jiao, J., \& Cao, X. (2011). Generation and TCA of Straight Bevel Gear Drive with Modified Geometry. Applied Mechanics and Materials, 86, 403-406. http://dx.doi.org/10.4028/www.scientific.net/AMM.86.403

Kawasaki, K., \& Shinma, K. (2009). Accuracy Measurement and Evaluation of Straight Bevel Gear Manufactured by End Mill Using CNC Milling Machine. ASME Journal of Mechanical Design, 131, 011001. http://dx.doi.org/10.1115/1.2988480

Kawasaki, K., Tsuji, I., Gunbara H., \& Houjoh H. (2015). Method for remanufacturing large-sized skew bevel gears using CNC machining center. Mechanism and Machine Theory, 92, 213-229. http://dx.doi.org/10.1016/j.mechmachtheory.2015.05.013

Kolivand, M., Ligata, H., Steyer, G., Benedict, D. K., \& Chen, J. (2015). Actual Tooth Contact Analysis of Straight Bevel Gears. ASME Journal of Mechanical Design, 137(9), 093302. http://dx.doi.org/10.1115/1. 4031025

Litvin, F. L., Tsung, W. J., Coy, J. J., \& Heine, C. (1987). Method for Generation of Spiral Bevel Gears with Conjugate Gear Tooth Surfaces. ASME Journal of Mechanical Design, 109, 163-170. http://dx.doi.org/ $10.1115 / 1.3267431$

Nalluveettil, S. J., \& Muthuveerappan, G. (1993). Finite element modeling and analysis of a straight bevel gear tooth. Computers and Structures, 48, 739-744. http://dx.doi.org/10.1016/0045-7949(93)90268-I

Özel,C., İnan, A., \& Özler, L. (2005). An Investigation on Manufacturing of the Straight Bevel Gear Using End Mill by CNC Milling Machine. ASME Journal of Manufacturing Science and Engineering, 127, 503-511. http://dx.doi.org/10.1115/1.1863256

Shih, Y. P. (2012). Mathematical Model for Face-Hobbed Straight Bevel Gears. ASME Journal of Mechanical Design, 134, 091006. http://dx.doi.org/10.1115/1.4007151

Shih, Y. P., \& Fong, Z. H. (2008). Flank Correction for Spiral Bevel and Hypoid Gears on a Six-Axis CNC Hypoid Generator. ASME Journal of Mechanical Design, 130, 062604. http://dx.doi.org/10.1115/1.2890112

Tsai, Y. C., \& Chin, P. C. (1987). Surface Geometry of Straight and Spiral Bevel Gears. ASME Journal of Mechanical Design, 109, 443-449. http://dx.doi.org/10.1115/1.3258815

Tsuji, I., Kawasaki, K., Gunbara, H., Houjoh, H., \& Matsumura, S. (2013). Tooth Contact Analysis and Manufacture on Multitasking Machine of Large-Sized Straight Bevel Gears with Equi-Depth Teeth. ASME Journal of Mechanical Design, 135, 034504. http://dx.doi.org/10.1115/1.4023324

Yassine, D., Ahmed, H., Lassaad, W., \& Mohamed, H. (2014). Effects of gear mesh fluctuation and defaults on the dynamic behavior of two-stage straight bevel system. Mechanism and Machine Theory, 82, 71-86. http://dx.doi.org/10.1016/j.mechmachtheory.2014.07.013

\section{Copyrights}

Copyright for this article is retained by the author(s), with first publication rights granted to the journal.

This is an open-access article distributed under the terms and conditions of the Creative Commons Attribution license (http://creativecommons.org/licenses/by/3.0/). 